\title{
Contrast-induced nephropathy: pharmacology, pathophysiology and prevention
}

\author{
Remy W. F. Geenen • Hylke Jan Kingma • Aart J. van der Molen
}

Received: 10 January 2012 /Revised: 24 August 2013 / Accepted: 4 September 2013 / Published online: 3 October 2013

(C) The Author(s) 2013. This article is published with open access at Springerlink.com

\begin{abstract}
Modern iodinated contrast media (CM) consist of one or two tri-iodobenzene rings. They differ from each other in the composition of the side chains, creating different molecules and thus different brand substances. After intravascular administration, all CM are distributed rapidly into intravascular and extracellular fluids. They are eliminated solely by glomerular filtration. In patients with normal renal function, CMs are eliminated within $24 \mathrm{~h}$. The pathophysiology of contrast-induced nephropathy $(\mathrm{CIN})$ is based on three distinct but interacting mechanisms: medullary ischaemia, formation of reactive oxygen species and direct tubular cell toxicity. The contribution of each of these mechanisms to the development of CIN in the individual patient remains unclear. CIN prevention is extensively described in guidelines, such as the recently updated guideline from the Contrast Media Safety Committee (CMSC) of the European Society of Urogenital Radiology (ESUR). The recent update is briefly discussed. Furthermore, it remains unclear if volume expansion with either $\mathrm{NaCl} 0.9 \%$ or $\mathrm{NaHCO}_{3} 1.4 \%$ is superior.

Teaching points

- After intravascular injection, CM are distributed over intravascular and extracellular fluids.

- CM are eliminated by glomerular filtration in patients with normal kidney function.
\end{abstract}

R. W. F. Geenen $(\bowtie)$

Department of Radiology, Medisch Centrum Alkmaar,

Wilhelminalaan 12, 1815 JD Alkmaar, Netherlands

e-mail: R.W.F.Geenen@mca.nl

\section{H. J. Kingma}

Department of Clinical Pharmacy, Stichting Apotheek der Haarlemse

Ziekenhuizen, Haarlem, Netherlands

A. J. van der Molen

Department of Radiology, Leiden University Medical Center,

Leiden, Netherlands
- CIN pathophysiology is based on medullary ischaemia, formation of reactive oxygen species (ROS) and tubular cell toxicity.

- It remains unclear if volume expansion with either $\mathrm{NaCl}$ $0.9 \%$ or $\mathrm{NaHCO}_{3} 1.4 \%$ is superior.

Keywords Contrast media · Clinical pharmacology · Pharmacokinetics · Kidney diseases · Guidelines as topic

\section{Introduction}

Contrast-induced nephropathy (CIN) refers to acute kidney injury (AKI) after intravenous or intra-arterial administration of contrast media (CM). Several definitions and classifications on AKI exist and are proposed in the nephrological literature $[1,2]$ The most widely used CIN definition is from the Contrast Media Safety Committee (CMSC) of the European Society of Urogenital Radiology (ESUR): an increase in serum creatinine (SC) of at least $25 \%$ or $44 \mu \mathrm{mol} / \mathrm{l}$ within 3 days after $\mathrm{CM}$ administration in absence of an alternative aetiology [3]. The incidence is highly dependent on renal function prior to $\mathrm{CM}$ administration and additional risk factors, of which diabetes mellitus is the most important one. Incidence varies from less than $2 \%$ in the general population up to $50 \%$ in patients with advanced kidney disease [4]. CIN is the third most common cause of hospital acquired renal failure, with an incidence of $11 \%$ [5]. Furthermore, CIN is associated with increased morbidity and mortality within 2 years following occurrence [3, 4].

In recent years, a controversy emerged as to whether CIN incidence is dependent on the administration route. Recently updated guidelines state that the CIN incidence is higher after intra-arterial administration than after intra-venous administration [3]. This is supported by literature, for example, intraarterial peripheral digital subtraction angiography has shown a CIN incidence of up to $14.3 \%$ [6]. A recent meta-analysis 
regarding CIN incidence after contrast-enhanced computed tomography (CT) has shown a pooled CIN incidence of $6.4 \%$ [7]. In a group of 747 patients, who underwent 944 procedures with intra-venous $\mathrm{CM}$ administration, $\mathrm{CIN}$ incidence was $2.4 \%$. All high-risk patients received pre- and posthydration in accordance with current guidelines [8]. On the other hand, a recently published study, describing 170 patients who received both intra-arterial and intra-venous $\mathrm{CM}$ within 1 year, showed a similar CIN incidence of $14 \%$ in the intraarterial group and $11.7 \%$ in the intra-venous group. It was concluded that CIN incidence is similar after intra-arterial and intravenous CM administration, after adjustment for patientrelated risk factors [9].

Second, several authors question the existence of CIN. In a 2006 published literature analysis, the authors found only two articles on intra-venous CM administration with a control group that received no CM. In both articles, the incidence of significant changes in SC was not significantly different between the group receiving intra-venous $\mathrm{CM}$ and the group receiving no $\mathrm{CM}[10]$. A change in $\mathrm{SC}$ of at least $25 \%$ during a 5 -day period occurred in more than $50 \%$ of patients who had not received CM [11]. The authors conclude that the role of CM in nephropathy may have been overestimated. A recently published meta-analysis describes a similar incidence of acute kidney injury between the group receiving $\mathrm{CM}$ and the control group [12]. In a recently published retrospective study of over $157,000 \mathrm{CT}$ scans in over 53,000 patients, no significant difference in acute kidney injury was found between contrast-enhanced and non-contrast scans [13]. As a counterbalance, another recently published retrospective study showed that CIN does exist after intra-venous CM administration, but only in subtypes of patients [14]. All patients who underwent CT over a 10-year period with sufficient SC data and stable renal function were included, 8,826 underwent nonenhanced CT and 8,826 underwent contrast-enhanced CT. Intra-venous low-osmolar $\mathrm{CM}$ proved to be a nephrotoxic risk factor in patients with a stable estimated glomerular filtration rate (eGFR) less than $30 \mathrm{ml} / \mathrm{kg} / 1.73 \mathrm{~m}^{2}$, with a trend towards significance at eGFR $30-44 \mathrm{ml} / \mathrm{kg} / 1.73 \mathrm{~m}^{2}$. Intra-venous low-osmolar $\mathrm{CM}$ were not risk factors in patients with eGFR $\geq 45 \mathrm{ml} / \mathrm{kg} / 1.73 \mathrm{~m}^{2}$ [14]. CIN incidence in the group with eGFR $\leq 30 \mathrm{ml} / \mathrm{kg} / 1.73 \mathrm{~m}^{2}$ was $36.4 \%$, compared with $19.4 \%$ in the non-enhanced CT group [14].

Although randomised controlled trials with a control group receiving no $\mathrm{CM}$ are widely lacking, results of these recently published retrospective studies provide a trend that CIN incidence has probably been overestimated in the past, but that CIN can occur in patients with decreased kidney function.

The following article reviews the pharmacology of $\mathrm{CM}$, the pathophysiology of CIN and discusses some preventive strategies, all for iodinated CM.

\section{Pharmacology of CM}

History

The modern era of CM started back in 1953 when Vernon Wallingford, a chemist working for the Mallinckrodt Company in St. Louis, MO, USA, synthesised a new class of chemical compounds. This molecule contained three iodine atoms covalently bound to an aromatic ring structure, a so-called benzoic acid derivate [15].

The compound Wallingford synthesised was called sodium acetrizoate (Fig. 1) and was marketed as Urokon ${ }^{\circledR}$. This was the first ionic, high-osmolar $\mathrm{CM}$ and it set a new standard in $\mathrm{CM}$. Soon 'me too' $\mathrm{CM}$ were developed, such as sodium diatrizoate (Urografin ${ }^{\circledR}$; Schering, Berlin, Germany) in 1954 and sodium iothalamate (Conray; Mallinckrodt, St. Louis, MO, USA) in 1963. These CM were the dominant CM throughout the 1960s-1980s and sodium diatrizoate still remains in use today for non-vascular radiology exams [16-18].

During the period in which ionic $\mathrm{CM}$ were introduced and administered extensively, it became clear that the $\mathrm{CM}$ could cause serious adverse effects related to the high osmolality and ionicity of the injected fluids. Torsten Almèn, a Swedish radiologist, realised the role of osmolality when he observed pain during administration of CM in angiography and compared it to swimming in the almost isotonic Baltic Sea with the eyes open which does not hurt. He hypothesised that high osmolality caused the pain and developed a chemical process to covert high-osmolar ionic CM into low-osmolar non-ionic CM. This resulted in the synthesis of metrizamide in 1968 (Fig. 2) [19]. Only after several pharmaceutical companies declined Almèn's ideas on low-osmolar $\mathrm{CM}$ was he able to persuade a Norwegian pharmaceutical company, Nyegaard, to further develop and market metrizamide (Amipaque ${ }^{\mathbb{R}}$ ). In the 1970s and 1980s the second generation non-ionic CM (Fig. 3) with increased solubility, such as iohexol (Omnipaque ${ }^{\circledR}$; GE, Amersham, UK), iopromide (Ultravist ${ }^{\circledR}$; Bayer Healthcare, Berlin, Germany), iomeprol (Iomeron ${ }^{\circledR}$; Bracco, Milano, Italy), ioversol (Optiray ${ }^{\mathbb{R}}$; Mallinckrodt, St. Louis, MO, USA) and Iobitridol (Xenetix ${ }^{\circledR}$; Guerbet, Aulnay-sous-Bois, France),

Fig. 1 The structural formula of sodium acetrizoate (Urokon); the first high-osmolar and ionic contrast agent

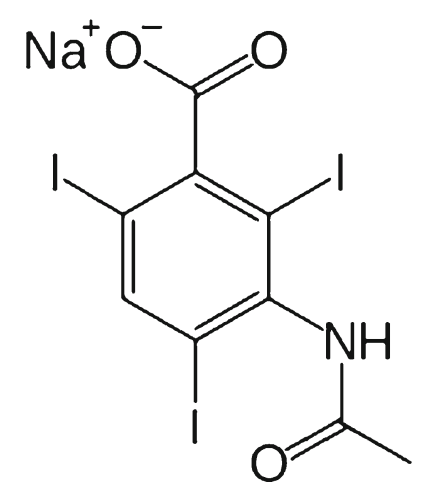




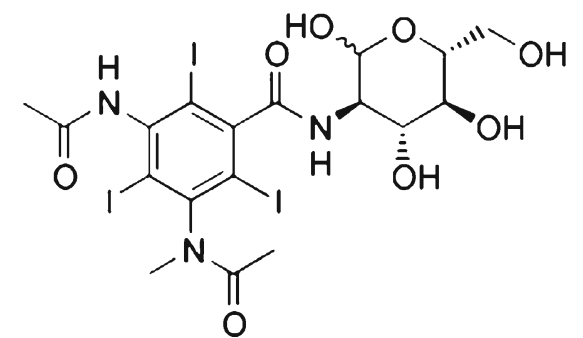

Fig. 2 The structural formula of metrizamide (Amipaque); the first nonionic contrast medium developed by Almen et al.

were developed and introduced in patient care in the next decade $[16,17]$.

Simultaneous to the development of the new low-osmolar $\mathrm{CM}$ was the introduction of an ionic dimeric compound, meglumine-sodium ioxaglate (Hexabrix ${ }^{\circledR}$; Guerbet, Aulnaysous-Bois, France) in 1979. Furthermore, non-ionic dimers were developed which proved to be iso-osmolar to blood. First, the iso-osmolar iotrolan (Isovist ${ }^{\circledR}$; Bayer Healthcare, Berlin, Germany) was introduced in 1994 and soon after its introduction withdrawn due to a high reported number of delayed reactions. Currently, the only non-ionic dimer (Fig. 4) on the market is iodixanol (Visipaque ${ }^{\circledR}$; GE, Amersham, UK) [20-23]. Since 1995, not a single iodinated contrast medium has been introduced which is still marketed internationally today.

In summary, currently four types of contrast medium are available. High-osmolar ionic monomers, low-osmolar ionic dimers, low-osmolar non-ionic monomers and iso-osmolar non-ionic dimers (Table 1).

\section{Chemical composition}

The tri-iodobenzene basis of sodium acetrizoate molecule contains $84 \%$ iodine and thus it displays excellent radioopaque properties. The other positions on the aromatic ring, numbers 1,3 and 5, are available for side chains to improve physicochemical and pharmacokinetic properties such as solubility, osmolality, protein binding and tolerance [15-18].

The hydrophilic side chains in sodium acetrizoate are an acid group (- $\mathrm{COOH}$ at position 1$)$ and an acetamido group

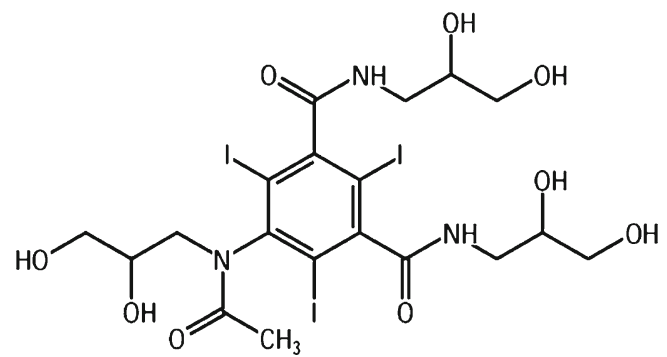

Fig. 3 The structural formula of iohexol (Omnipaque); an example of a highly soluble polycarboxylated contrast medium
( $-\mathrm{NHCOCH}_{3}$ at position 3$)$ to enhance solubility, salt formation and to reduce protein binding, as can be seen in Fig. 1 . The $-\mathrm{COOH}$ group at position 1 is responsible for the ionicity, as it forms a cation conjugated with sodium or meglumine in solutions. Adding another acetamido group at position 5 created sodium diatrizoate $[16,17]$.

In metrizamide, the first non-ionic iodinated contrast medium developed by Almen and colleagues, an acetamide (-NHCOCH3) group was placed at both positions 3 and 5 of the aromatic ring. Novel in the development of metrizamide was adding a derivative of glucose, containing four hydroxyl groups, at position 1 of the aromatic ring. This proved an important step to decrease the osmolality by eliminating the effect of positive and negative ions in the contrast solution and retaining radio-opaque properties [16-19].

Metrizamide proved poorly soluble and thus was of limited use in intravenous contrast administration. Soon, however, highly soluble polycarboxylated agents (Fig. 3) followed, such as iohexol and ioversol. The solubility in these agents is improved by adding more carboxyl groups to the triiodinated aromatic structure [16-19].

Reduction of osmolality and further increasing the number of iodine atoms in the molecules led to the development of dimeric non-ionic CM. These structures consist of two aromatic rings containing a total of six iodine atoms covalently bound to the ring (Fig. 4). The introduction of these non-ionic dimers proved to reduce osmolality without significantly influencing radio-opaque quality or systemic reactions upon administration. Generally, dimers display a higher viscosity than monomeric CM $[16,17]$.

Pharmacokinetic properties

After intravenous administration, $\mathrm{CM}$ are distributed rapidly into extracellular body compartments, and rapid decreases in plasma concentrations can be measured. The plasma concentration-time plot of contrast medium pharmacokinetics displays the characteristics of a classical bi-exponential model.

Several factors determine the pharmacokinetic properties of a contrast medium. The side chains of the aromatic rings influence solubility, osmolality, protein binding and toxicity profile. Lipophilic side chains, for example, will lower the solubility in water and tend to have high plasma protein binding, whereas a carboxyl $(-\mathrm{COOH})$ group can form salts and enhance solubility and osmolality. Hydrophilic side chains such as acetamide groups $\left(-\mathrm{NHCOCH}_{3}\right)$ and polyhydroxylated groups (containing several $-\mathrm{OH}$ groups) further improve solubility in water, tolerability and are able to reduce protein binding. The latter property is of importance to ensure rapid glomerular filtration. Non-ionic CM generally are very hydrophilic $[16,17]$.

The amount of particles in a certain volume determines the osmolality. It takes both cell membrane penetrating particles 
Fig. 4 The structural formula of iodixanol (Visipaque); a nonionic dimer consisting of two aromatic rings, each containing three iodine atoms<smiles>CC(=O)N(CC(O)CN(C(C)=O)c1c(I)c(C(=O)NCC(O)CO)c(I)c(C(=O)NCC(O)CO)c1I)c1c(I)c(C(=O)NCC(O)CO)c(I)c(C(=O)NCC(O)CO)c1I</smiles>

and non-penetrating particles into account. Penetrating solutes can enhance the cell volume by attracting water after passing the cell membrane, whereas non-penetrating solutes outside the cell will attract water from the cell. High osmolality is one of the co-factors responsible for tolerability of $\mathrm{CM}$. Ionic $\mathrm{CM}$ are molecules with an electrical charge and solutions in water contain cations such as sodium or meglumine. In general, these solutions contain more particles per millilitre and thus have a higher osmolality than non-ionic CM. High osmolar $\mathrm{CM}$ are less tolerable than low-osmolar or iso-osmolar CM.

Table 1 Pharmacological and pharmacokinetic parameters of iodinated CM [23]

\begin{tabular}{|c|c|c|c|c|c|c|c|}
\hline $\begin{array}{l}\text { Generic name (brand name), } \\
\text { year of introduction }\end{array}$ & mg I per ml & Ionic? & Monomer? & Osmolality mOsm $/ \mathrm{kg}$ & Viscosity $\mathrm{mPa} \cdot \mathrm{s}$ & $\mathrm{t}^{1} / 2 \mathrm{D} \min$ & $t^{1 / 2} E L \min ^{a}$ \\
\hline $\begin{array}{l}\text { Amidotrizoic acid } \\
\text { (Urografin), } \\
1955\end{array}$ & 146 & Yes & Yes & 710 & $2.2 @ 20^{\circ} \mathrm{C} 1.4 @ 37^{\circ} \mathrm{C}$ & 30 & 120 \\
\hline $\begin{array}{l}\text { Ioxitalaminic acid } \\
\text { (Telebrix), } \\
1969\end{array}$ & 350 & Yes & Yes & 2.130 & $15.1 @ 20{ }^{\circ} \mathrm{C} 7.5 @ 37{ }^{\circ} \mathrm{C}$ & $\mathrm{c}$ & 66 \\
\hline $\begin{array}{l}\text { Ioxaglate } \\
\text { (Hexabrix), } \\
1979\end{array}$ & 320 & Yes & No & 600 & $7.5 @ 20{ }^{\circ} \mathrm{C} 2.2 @ 37^{\circ} \mathrm{C}$ & 15 & 60 \\
\hline $\begin{array}{l}\text { Iopromide } \\
\text { (Ultravist), } \\
1979\end{array}$ & 370 & No & Yes & 770 & $22.0 @ 20{ }^{\circ} \mathrm{C} 10.0 @ 37{ }^{\circ} \mathrm{C}$ & $3(1-5)$ & 120 \\
\hline $\begin{array}{l}\text { Iohexol } \\
\text { (Omnipaque), } \\
1983\end{array}$ & 350 & No & Yes & 780 & $23.3 @ 20{ }^{\circ} \mathrm{C} 10.6 @ 37{ }^{\circ} \mathrm{C}$ & c & 120 \\
\hline $\begin{array}{l}\text { Iotrolan } \\
\quad \text { (Isovist), } \\
1988\end{array}$ & 300 & No & No & 320 & $16.4 @ 20{ }^{\circ} \mathrm{C} 8.1 @ 37{ }^{\circ} \mathrm{C}$ & $\mathrm{c}$ & $\mathrm{c}$ \\
\hline $\begin{array}{l}\text { Ioversol } \\
\text { (Optiray), } \\
1989\end{array}$ & 350 & No & Yes & 790 & $14.5 @ 25^{\circ} \mathrm{C} 8.0 @ 37{ }^{\circ} \mathrm{C}$ & $\mathrm{c}$ & $96-120$ \\
\hline $\begin{array}{l}\text { Iomeprol } \\
\quad \text { (Iomeron), } \\
1994\end{array}$ & 350 & No & Yes & 618 & $14.5 @ 20{ }^{\circ} \mathrm{C} 7.5 @ 37{ }^{\circ} \mathrm{C}$ & $10-35 \& 90-130^{b}$ & 110 \\
\hline $\begin{array}{l}\text { Iobitridol } \\
\quad \text { (Xenetix), } \\
1995\end{array}$ & 350 & No & Yes & 915 & $21.0 @ 20^{\circ} \mathrm{C} 10.0 @ 37{ }^{\circ} \mathrm{C}$ & $\mathrm{c}$ & 108 \\
\hline $\begin{array}{l}\text { Iodixanol } \\
\text { (Visipaque), } \\
1995\end{array}$ & 320 & No & No & 290 & $25.4 @ 20{ }^{\circ} \mathrm{C} 11.4 @ 37{ }^{\circ} \mathrm{C}$ & 21 & 120 \\
\hline
\end{tabular}

a Approximate elimination half-life after intravenous injection in patients with normal renal function

${ }^{\mathrm{b}}$ Iomeprol exhibits biphasic distribution with a first short period and a second longer period

${ }^{c}$ Data after intravenous infusion unknown 
Non-ionic CM do not have an electrical charge and generally have a lower osmotic contribution than ionic $\mathrm{CM}[16,17]$. Generally, if a larger number of iodine atoms are covalently bound in a molecule, this molecule will be more difficult to dissolve in water. The addition of large numbers of hydrophilic carboxyl groups, cation forming groups or hydroxyl groups is needed to achieve adequate solubility in aqueous solutions for use of the molecule as a contrast agent.

Another important physicochemical property is viscosity. Viscosity, best described as thickness or internal friction, of a fluid determines the infusion rate that can be achieved. Fluids with a high viscosity will be infused over a longer period of time compared with fluids with a low viscosity when the same infusion system is used. After intravenous injection, fluids with a high viscosity can influence local circulation on a larger scale than fluids with a low viscosity, since the latter will mix more easily with blood.

Recent data from animal studies suggest that iso-osmolar non-ionic dimers compared with low-osmolar non-ionic monomers significantly increase urine viscosity, lead to increased kidney iodine retention and increase the formation of vacuoles in the renal tubular epithelium of the cortex predominantly in the proximal and distal tubulus [24].

After intravascular administration, CM are distributed rapidly over intravascular and extracellular fluids, i.e. the $\mathrm{CM}$ have a short distribution half-life $\left(t^{1} / 2 \mathrm{~d}\right)$. Usually, the time for the $\mathrm{CM}$ to distribute evenly over the fluids is several minutes, ranging from 2 to $30 \mathrm{~min}$. Plasma protein binding is approximately 1-3\% [16].

$\mathrm{CM}$ are not metabolised in the human body, but eliminated quickly through glomerular filtration by the kidney. The time to clear half of the amount of contrast medium in the blood, or elimination half-life $\left(t^{1} / 2_{\mathrm{el}}\right)$, is approximately $1-2 \mathrm{~h}$.

In patients with normal renal function approximately $100 \%$ of the contrast medium is excreted in the first $24 \mathrm{~h}$ after administration. In patients with decreased renal function the elimination half-life can increase to $40 \mathrm{~h}$ or more [25]. Alternative routes of elimination, such as biliary elimination, are slow. Haemodialysis and peritoneal dialysis are efficient methods to remove CM from the blood $[25,26]$.

An overview of physicochemical and pharmacokinetic properties can be found in Table 1 .

\section{Pathophysiology of CIN}

The pathophysiology of CIN is complex and partially understood. What exactly happens inside a human kidney in vivo can only be speculated from the results of mainly animal and laboratory studies.

Under physiological resting conditions, $25 \%$ of the cardiac output is directed towards the kidneys. The majority is directed towards the cortex, to optimise glomerular filtration and reabsorption of water and salts. The medullary blood flow is low. Its function is to preserve osmotic gradients and enhance urinary concentration [27]. Blood flow to the renal medulla is derived from efferent arterioles of juxtamedullary glomeruli. At the corticomedullary junction, these efferent arterioles give rise to the so-called distal vasa recta (DVR). These DVR gradually form a capillary bed that penetrates deep into the inner medulla. These capillaries eventually coalesce to form ascending vasa recta (AVR). The transformation from DVR to capillary to AVR occurs gradually with accompanying histological changes in the composition of the vessel wall [28].

Hypoxic medullary injury plays a critical role in CIN [29]. This is caused by three different but potentially interacting pathways: haemodynamic effects of $\mathrm{CM}$, the effect of reactive oxygen species (ROS) and free radicals and direct CM molecule tubular cell toxicity [30].

\section{Haemodynamic effects}

Under physiological circumstances, regional $\mathrm{PO}_{2}$ levels of the renal medulla can be as low as $20 \mathrm{mmHg}$ [31]. The most vulnerable part of hypoxic damage is the deeper portion of the outer medulla that contains the metabolically active thick ascending limbs of the loop of Henle. In this part of the tubular system, an osmotic gradient is generated by active reabsorption of sodium, a process that requires a large amount of oxygen [27]. The haemodynamic response to intra-arterial injection of contrast medium is biphasic: a brief initial increase in renal blood flow, followed by a prolonged decline of 10-25\% below baseline [29, 30, 33]. This predomintantly reflects a decline in cortical blood flow, as $10 \%$ of renal blood flow represents medullary flow [29] Declines of outer medullary $\mathrm{PO}_{2}$ by $50-67 \%$ after contrast medium administration to $9-15 \mathrm{mmHg}$ have been reported $[29,32]$. The mechanism for medullary hypoxia is a combination of a decline in regional microcirculatory blood flow and increased oxygen demand of tubular cells [29, 32].

Injection of contrast medium leads to a transient increase in renal plasma flow, glomerular filtration and urinary output [29]. The higher the osmolality of the injected contrast medium, the higher these effects are. Both by osmotic load, as by the effect of endothelin release, more sodium has to be reabsorbed by distal tubular cells $[29,31,32]$. This leads to increased oxygen consumption [31,33].

The decline in regional blood flow has been attributed to the response of vaso-active mediators to contrast medium administration. Basically, an imbalance occurs between vasoconstrictive and vasodilatative mediators. Many mediators have been related to contrast medium administration. Prominent medullary vasodilatators are adenosine, dopamine, nitric oxide (NO), atrial natriuretic peptide (ANP) and prostaglandin $\mathrm{E}_{2}[27,31,33]$. Vasconstrictors act more on the cortical vessels, to decrease glomerular filtration [29]. Potent 
vasoconstrictors are vasopressin, angiotensin II and endothelin [27, 31]. Potential additional participants, both dilatative and constrictive in the pathophysiology, are: serotonin, bradykinin, leukotriens, histamine and catecholamines [33]. To what extent each mediator plays a role is unknown. Furthermore, the distribution of receptor mediator subtypes in the cortex and medulla may be responsible for different regional haemodynamic responses [29, 33].

More insight on the medullar microvasculature response to CM has been given by Sendeski et al. [34]. The average DVR diameter is $12-18 \mu \mathrm{m}$, close to that of a red blood cell. On isolated rat DVRs, it was shown that micro-perfusion with Iodixanol leads to a diameter reduction of $48 \%$. This was due to a decreased NO production and an increase reactivity of DVR to angiotensin II. Addition of a free radical scavenger, prevented Iodixanol and angiotensin-II-induced vasoconstriction [34]. Additional research from the same group showed that Iodixanol has a more pronounced vasconstrictive effect on afferent arterioles than on efferent arterioles. Decreased NO availability and increased superoxide concentration explained the increased tone and reactivity of afferent arterioles [35].

\section{Reactive oxygen species (ROS)}

Free radicals are atoms or molecules that contain one or more unpaired electrons [30]. Examples are superoxide $\left(\mathrm{O}_{2}{ }^{-}\right)$and hydroxyl radical $\left(\mathrm{OH}^{-}\right)$[32]. These molecules are changed into water after successive reduction reactions [30]. Less aggressive reacting molecules, such as $\mathrm{H}_{2} \mathrm{O}_{2}$, are called ROS $[30,32]$. Under physiological conditions, medullary tubular
ROS formation plays an important role in cellular signalling processes, regulation of regional microcirculation and tubular transport by its effects on NO concentration and tubular transport activity [36]. Medullary hypoxia develops after contrast medium administration, both by decreased medullary blood flow and increased oxygen demand of tubular cells due to increased sodium reabsorption. This leads to increased ROS formation and oxidative stress, an imbalance between oxidants and antioxidants in favour of oxidants. The mechanisms of increased ROS formation are complex and only partially understood [36]. Once exceeding the cellular scavenging capacities, ROS lead to the so-called ischaemia-reperfusion injury [36]. This refers to cellular injury caused by combined effects of hypoxia and ROS-mediated oxidative damage. The latter affects mitochondrial and nuclear DNA, membrane lipids and cellular proteins [36]. ROS play an important role in altered renal microcirculation. They trigger and increase angiotensin-II- and endothelin-I-induced vasoconstriction. Furthermore, bioavailability of the vasodilatative NO is reduced by ROS [36].

\section{Tubular cell toxicity}

Direct toxic effects of CM can only be studied in vitro, for the effect of other cell injury mechanisms such as hypoxia, can be ruled out [37]. In general, the toxic effects of high osmolar CM are more pronounced than the effects of low- or iso-osmolar $\mathrm{CM}$ [37]. Cytoxic effects of $\mathrm{CM}$ on glomerular mesangial cells include apoptotic effects, associated with elevated intracellular ROS levels [37]. The latter shows how pathophysiological

Table 2 Summary of practical aspects of guidelines

\begin{tabular}{|c|c|c|}
\hline & ESUR & ACR \\
\hline $\begin{array}{l}\text { Indications for SC measurement } \\
\text { prior to contrast medium } \\
\text { administration }\end{array}$ & $\begin{array}{l}\text { - Age }>70 \\
\text { - History of: renal disease, renal cancer, } \\
\text { proteinuria, diabetes mellitus, } \\
\text { hypertension, gout, recent nephrotoxic drugs } \\
\text { - Known eGFR }<60 \\
\text { - Intra-arterial contrast medium administration }\end{array}$ & $\begin{array}{l}\text { - Age }>60 \\
\text { - History of: renal disease, renal cancer, } \\
\text { renal surgery, kidney transplant, } \\
\text { single kidney, dialysis, hypertension } \\
\text { requiring medical therapy, } \\
\text { diabetes mellitus } \\
\text { - Use of metformin }\end{array}$ \\
\hline $\begin{array}{l}\text { Interval SC measurement - contrast } \\
\text { medium administration }\end{array}$ & Within 7 days & No universally accepted interval \\
\hline Volume expansion with $\mathrm{NaCl} 0.9 \%$ i.v. & $\begin{array}{l}1-1.5 \mathrm{ml} / \mathrm{kg} / \mathrm{h} \geq 6 \mathrm{~h} \text { before, } \geq 6 \mathrm{~h} \text { after } \\
\text { contrast medium administration }\end{array}$ & $\begin{array}{l}100 \mathrm{ml} / \mathrm{h} 6-12 \mathrm{~h} \text { before, } 4-12 \mathrm{~h} \text { after } \\
\mathrm{CM} \text { administration }\end{array}$ \\
\hline Volume expansion with $\mathrm{NaHCO}_{3} 1.4 \%$ & $\begin{array}{l}3 \mathrm{ml} / \mathrm{kg} / \mathrm{h} 1 \mathrm{~h} \text { before, } 1 \mathrm{ml} / \mathrm{kg} / \mathrm{h} 6 \mathrm{~h} \text { after } \\
\text { contrast medium administration }\end{array}$ & No definite results \\
\hline Emergency volume expansion & Start as early as possible & No guidelines \\
\hline $\begin{array}{l}\text { Post contrast medium administration } \\
\text { SC measurement }\end{array}$ & $\begin{array}{l}\text { Determine eGFR } 48-72 \mathrm{~h} \text { post contrast } \\
\text { medium administration in high risk } \\
\text { patients }\end{array}$ & No guidelines \\
\hline Nephrotoxic drugs & $\begin{array}{l}\text { Cyclosporin } \\
\text { Cisplatin } \\
\text { Aminoglycosides } \\
\text { NSAID }\end{array}$ & No guidelines \\
\hline
\end{tabular}


CIN mechanisms interact and enhance each other. More effects of CM on tubular cells have been described, including redistribution of membrane proteins, reduction of extracellular $\mathrm{Ca}^{2+}$, DNA fragmentation, disruption of intercellular junctions, reduced cell proliferation, apoptosis and altered mitochondrial function [37].

In conclusion, CIN is a consequence of medullary ischaemia by both increased oxygen consumption of tubular cells and decreased perfusion. This leads to the formation of ROS, which enhance the effect of vasoconstrictive mediators and reduce the bioavailability of vasodilatative mediators. Furthermore, ROS formation leads to oxidative damage to tubular cells. CM also have a direct toxic effect on tubular cells, with increased ROS formation as a consequence. These three interacting pathways can finally lead to tubular necrosis.

Prevention

Regarding prevention, international guidelines exist, such as the ACR manual on contrast media [38]. Probably the most widely used guideline on CIN prevention is the one by the CMSC of the ESUR, which can be easily checked on-line and has recently been updated $[3,26]$. A summary on the practical aspects of both guidelines is displayed in Table 2 .

\section{Updated CIN Guideline by the CMSC of the ESUR}

After more than 10 years, the CMSC guideline on CIN was in need of revision and the updated guideline was published very recently [3]. The list of patient-related risk factors has been updated and now also includes factors related to cardiovascular instability like a low haematocrit level, periprocedural hypotension, a recent myocardial infarction $(<24 \mathrm{~h})$, and use of an intraaortic balloon pump, which can be present in many clinical high-care patients. The procedure-related risk factors have not changed to a great deal, but in high risk patients it is important to use the minimal dose of low- or iso-osmolar contrast medium necessary for a diagnostic examination. An essential, but often forgotten, point is that alternative imaging methods should be considered first and in high-risk patients scheduled for CT, there is still an underuse of MRI in daily practice.

One of the major new things in the guideline is the fact that the route of contrast medium administration is discriminative in assessing the risk. Based on the data and reviews of intravenous $\mathrm{CM}$ administration studies, it was concluded that the risk of CIN in intravenous CM administration is lower than the risk of intra-arterial $\mathrm{CM}$ administration. In intravenous $\mathrm{CM}$ administration, several studies have shown that the risk of CIN increases if eGFR is $\leq 45 \mathrm{ml} / \mathrm{min} / 1.73 \mathrm{~m}^{2}$. For intra-arterial contrast medium administration a cut-off eGFR of $<60 \mathrm{ml} /$ $\min / 1.73 \mathrm{~m}^{2}$ has been maintained.

Volume expansion is still considered the backbone of CIN prevention, with no indication for pharmacological

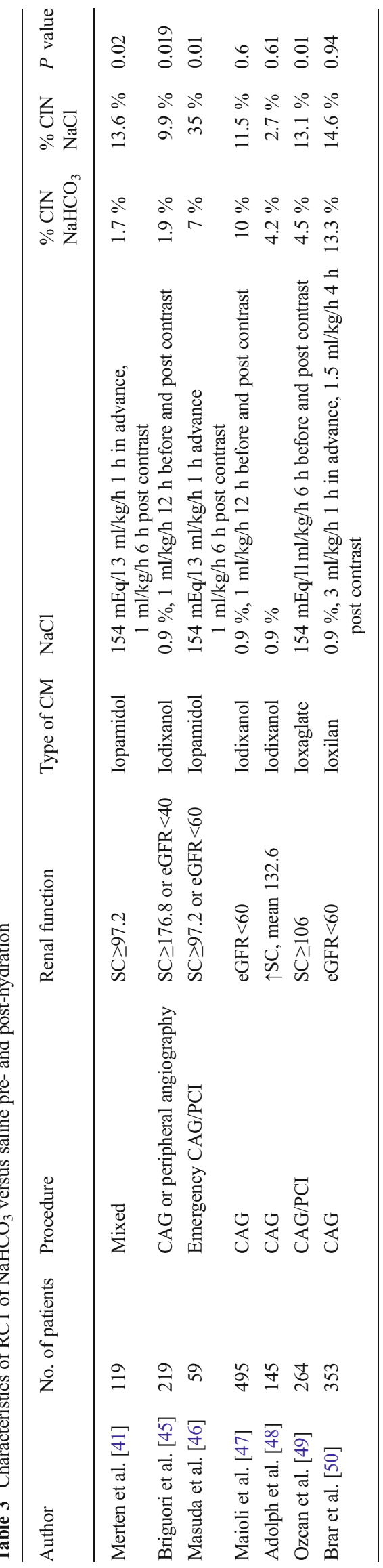


prophylaxis, such as N-acetylcysteine (NAC). The results of the published studies on NAC vary considerably, with most studies finding no significant benefit [39]. In the preventive schemes of fluid administration, intravenous is still considered superior to oral fluid administration due to a better control of the volume expansion. Intravenous infusion of $1.0-1.5 \mathrm{ml} / \mathrm{kg} /$ $\mathrm{h}$ saline $0.9 \%$ starting $6 \mathrm{~h}$ before and continuing $6 \mathrm{~h}$ after contrast medium administration has proven to be an effective prevention scheme. Another major new item in the guideline is the fact that intravenous administration of $3 \mathrm{ml} / \mathrm{kg} / \mathrm{h}$ sodium bicarbonate $1.4 \%$, starting $1 \mathrm{~h}$ before and continuing at a dose of $1 \mathrm{ml} / \mathrm{kg} / \mathrm{h}$ for $3 \mathrm{~h}$ after the contrast medium administration is an adequate alternative in elective examinations, and the preferred schedule in emergency situations.

Volume expansion: bicarbonate versus saline

Central volume expansion leads to an increased intravascular volume. As a consequence, renal blood flow and diuresis increases, leading to decreased contact time of contrast medium with renal tubular cells. Supression of the renin-angiotensin system occurs, leading to a general renal vasodilatation $[3,4$, 40]. Volume expansion is a safe procedure, with six adverse events reported in 511 procedures (1.2\%) [8].

An ongoing controversy in intravenous hydration is whether to use $\mathrm{NaCl} 0.9 \%$ or $\mathrm{NaHCO}_{3} 1.4 \%$ intravenously. $\mathrm{NaHCO}_{3}$ $1.4 \%$ is commercially available and therefore widely used for volume expansion. It equals $\mathrm{NaHCO}_{3} 167 \mathrm{mEq} / \mathrm{l}$, the closest commercially available product to the researched $\mathrm{NaHCO}_{3}$ $154 \mathrm{mEq} / \mathrm{l}$. The hypothesis behind the possible increased protective effect of $\mathrm{NaHCO}_{3}$ is as follows: the use of $\mathrm{NaHCO}_{3}$ leads to alkalisation of renal tubular fluid; in a more alkali environment, ROS formation is impaired [3, 40].

The first published randomised controlled trial (RCT) on this subject by Merten et al. [41] described 119 patients undergoing either coronary angiography (CAG), CT, diagnostic or therapeutic angiography or TIPS procedure. They were randomly assigned to receive either $\mathrm{NaCl} 154 \mathrm{mEq} / \mathrm{l}$ in $5 \%$ dextrose and $\mathrm{H}_{2} \mathrm{O}$ or $\mathrm{NaHCO}_{3} 154 \mathrm{mEq} / \mathrm{l}$ in $5 \%$ dextrose and $\mathrm{H}_{2} \mathrm{O}$. Both solutions were intravenously administered at $3 \mathrm{ml} / \mathrm{kg} / \mathrm{h}$ for $1 \mathrm{~h}$ before $\mathrm{CM}$ administration and $1 \mathrm{ml} / \mathrm{kg} / \mathrm{h}$ for $6 \mathrm{~h}$ after $\mathrm{CM}$ administration. $\mathrm{CIN}$ incidence in the $\mathrm{NaHCO}_{3}$ group was $1.7 \%$ versus $13.6 \%$ in the $\mathrm{NaCl}$ group [41]. This RCT shows convincing evidence in favour of $\mathrm{NaHCO}_{3}$ hydration, but the used hydration schedule for $\mathrm{NaCl}$ was rather unusual. Most hydration schedules with $\mathrm{NaCl}$, use isotonic saline $(0.9 \%)$ and a much longer pre- and post-hydration time of up to $12 \mathrm{~h}$.

The results of this RCT, triggered the performance of new RCTs regarding $\mathrm{NaHCO}_{3}$ versus $\mathrm{NaCl}$. Two trails compared the effect of a single bolus of $\mathrm{NaHCO}_{3}$ before CAG or PCI [42, 43]. Both RCTs showed significantly less CIN in the group treated with the $\mathrm{NaHCO}_{3}$ bolus $[42,43]$. One RCT created its own mixture of $\mathrm{NaHCO}_{3}$ with $\mathrm{NaCl} 0.45 \%$ [44]. The results of this trial are therefore not comparable to any of the other published RCTs. For four other RCTs, the schedule of Merten et al. [41] was used for prior and post $\mathrm{NaHCO}_{3}$ hydration, as described in the section above. This schedule has been compared with several $\mathrm{NaCl}$ schedules in mainly cardiology patient groups with different stages of renal impairment [45-48]. Another RCT uses the same $\mathrm{NaHCO}_{3}$ concentration, but administers $1 \mathrm{ml} / \mathrm{kg} / \mathrm{h}$ from $6 \mathrm{~h}$ before till $6 \mathrm{~h}$ after contrast medium administration [49]. The final RCT uses a more or less comparable schedule of $\mathrm{NaHCO}_{3} 150 \mathrm{mEq} / \mathrm{l}$ at a rate of $3 \mathrm{ml} / \mathrm{kg} / \mathrm{h}$ for $1 \mathrm{~h}$ before contrast medium administration and $1.5 \mathrm{ml} / \mathrm{kg} / \mathrm{h}$ for $4 \mathrm{~h}$ after CM administration [50] The results of these more or less comparable RCTs are displayed in Table 3.

Recently an abstract has been published online describing the results of a randomised controlled trial regarding $1 \mathrm{~h}$ prehydration with $250 \mathrm{ml} \mathrm{NaHCO} 31.4 \%$ versus $4-12 \mathrm{~h}$ pre- and post-hydration with $1,000 \mathrm{ml} \mathrm{NaCl} 0.9 \%$. CIN incidence was $3.3 \%$ in the $\mathrm{NaHCO}_{3}$ group and $3.7 \%$ in the $\mathrm{NaCl} 0.9 \%$ group [51]. This indicates that a short $\mathrm{NaHCO}_{3}$ pre-hydration schedule can be safely used in CIN prevention, which can lead to a reduction in hospital stay and therefore a reduction in costs [51].

From these seven more or less comparable RCTs on intravenous volume expansion, four show a statistically significant difference in favour of $\mathrm{NaHCO}_{3}$. None of these RCT's has an outcome in favour of $\mathrm{NaCl}$. Therefore, the $\mathrm{CMSC}$ conclusion that pre- and post-hydration with $\mathrm{NaHCO}_{3}$ is at least equal to $\mathrm{NaCl}$, is justifiable.

\section{Conclusions}

The pharmacology of iodinated CM is simple. A quick distribution within the extra-vascular space, no metabolisation and excretion solely by glomerular filtration. The pathophysiology of CIN has three branches that interact with each other: haemodynamic effects, formation of ROS and tubular cell toxicity. Prevention is extensively described in guidelines. Recently, ESUR guidelines have been updated.

Conflict of interest The authors declare no conflicts of interest. No funding was received for this work.

Open Access This article is distributed under the terms of the Creative Commons Attribution License which permits any use, distribution, and reproduction in any medium, provided the original author(s) and the source are credited.

\section{References}

1. Fliser D, Laville M, Covic A, Fouque D, Vanholder R, Juillard L et al (2012) A European renal best practice (ERBP) position statement on the kidney disease improving global outcomes (KDIGO) clinical 
practice guidelines on acute kidney injury: Part 1: definitions, conservative managment and contrast-induced nephropathy. Nephrol Dial Transplant 27:4263-4272

2. Bellomo R, Kellum JA, Ronco C (2012) Acute kidney injury. Lancet 380:756-766

3. Stacul F, Van der Molen A, Reimer P, Webb JAW, Thomsen HS, Morcos SK et al (2011) Contrast induced nephropathy: updated ESUR contrast media safety committee guidelines. Eur Radiol 21: 2527-2541

4. Thomsen HS, Morcos SK, Barrett BJ (2008) Contrast-induced nephropathy: The wheel has turned 360 degrees. Acta Radiol 49:646657

5. Nash K, Hafeez A, Hou S (2002) Hospital-acquired renal insufficiency. Am J Kidney Dis 39:930-936

6. Karlsberg RP, Dohad SY, Sheng R (2010) Contrast-induced acute kidney injury (CI-AKI) following intra-arterial administration of iodinated contrast media. J Nephrol 23:658-666

7. Kooiman J, Pasha SM, Zondag W, Sijpkens YWJ, Van der Molen AJ, Huisman MV et al (2012) Meta-analysis: Serum creatinine changes following contrast enhanced CT imaging. Eur J Radiol 81:2554-2561

8. Balemans CEA, Reichert LJM, Schelven BIH, Van den Brand JAJG, Wetzels JFM (2012) Epidemiology of contrast material-induced nephropathy in the era of hydration. Radiology 263:706-713

9. Kooiman J, Le Haen PA, Gezgin G, De Vries JPP, Boersma D, Brulez HF et al (2013) Contrast-induced acute kidney injury and clinical outcomes after intra-arterial and intravenous contrast administration: risk comparison adjusted for patient characteristics by design. Am Heart J 165:793-799

10. Rao QA, Newhouse JH (2006) Risk of nephropathy after intravenous administration of contrast material: A critical literature analysis. Radiology 239:392-397

11. Newhouse JH, Kho D, Rao QA, Starren J (2008) Frequency of serum creatinine changes in the absence of iodinated contrast material: Implications for studies of contrast nephrotoxicity. AJR Am J Roentgenol 191:376-382

12. McDonald JS, McDonald RJ, Comin J, Wiliamson E, Katzberg RW, Hassan Murad M et al (2013) Frequency of acute kidney injury following intravenous contrast medium administration: A systematic review and meta-analysis. Radiology 276:119-128

13. McDonald RJ, McDonald JS, Bida JP, Carter RE, Fleming CJ, Misra $S$ et al (2013) Intravenous contrast material-induced nephropathy: causal of coincident phenomenon? Radiology 276:106-118

14. Davenport MS, Khalatbari Sm Cohan RH, Dillman JR, Myles JD, Ellis JH (2013) Contrast material-induced nephrotoxicity and intravenous low-osmolality contrast material: Risk stratification by using estimated glomerular filtration rate. Radiology 268:719-728

15. Wallingford VH (1953) The development of organic iodine compounds a x-ray contrast media. J Am Pharm Assoc (Baltim) 42:721728

16. Speck U (1999) Contrast media: overview, use and pharmaceutical aspects, 4th edn. Springer, Berlin Heidelberg New York, pp 8-83

17. Pollack HM (1998) History of iodinated contrast media. In: Thomson HS, Muller RN, Mattrey RF (eds) Trends in contrast media. Springer, Berlin Heidelberg New York, pp 3-19

18. Fischer HM (1987) Historical aspects of contrast media. In: Felix R (ed) Contrast media from the past tot the future. Symposium Berlin 1987. Georg Thieme, Stuttgart New York, pp 3-18

19. Almen T (1969) Contrast agent design. Some aspects on the synthesis of water soluble contrast agents of low osmolality. Theor Biol 24 : 216-226

20. Gonsette RE (1978) Animal experiments and clinical experiences in cerebral angiography with a new contrast agent (ioxaglic acid) with a low hyperosmolality. Ann Radiol (Paris) 21:271-273

21. Sovak M, Ranganathan R, Speck U (1982) Nonionic dimer: development and initial testing of an intrathecal contrast agent. Radiology 142:115-118
22. Scholz P, Weinmann HJ, Mützel W, Staks T (1989) Pharmacokinetics of iotrolan after intravenous injection into healthy volunteers. Fortschr Geb Rontgenstrahlen Nuklearmed Erganzungsbd 128:211-214

23. Bolstad B, Borch KW, Grynne BH, Lundby B, Nossen JO, Kloster YF et al (1991) Safety and tolerability of iodixanol. A dimeric, nonionic contrast medium: an emphasis on European clinical phases I and II. Invest Radiol 26(Suppl 1):S201-204

24. Lenhard DC, Frisk AL, Lengsfeld P, Pietsch H, Jost G (2013) The effect of iodinated contrast agent properties on renal kinetics and oxygenation. Invest Radiol 48:175-182

25. SmPC texts of the ICMs via the College ter Beoordeling van Geneesmiddelen (Medicines Evaluation Board) in The Netherlands http://www.cbg-meb.nl/cbg/nl Last accessed 24/08/2013: Amidotrizoic acid (Urografin); Iobitridol (Xenetix); Iodixanol (Visipaque); Iohexol (Omnipaque); Iomeprol (Iomeron); Iopromide (Ultravist); Ioversol (Optiray); Ioxaglate (Hexabrix); Ioxitalaminic acid (Telebrix).

26. European Society of Urogenital Radiology contrast media Safety Committee guidelines. Accesible at: http://www.esur.org/guidelines/ Last accessed 24/08/2013

27. Brezis M, Rosen S (1995) Hypoxia of the renal medulla-its implications for disease. N Engl J Med 332:647-655

28. Pallone TL, Turner MR, Edwards A, Jamison RL (2003) Countercurrent exchange in the renal medulla. Am J Physiol Regul Integr Comp Physiol 284:R1153-R1175

29. Heyman SN, Rosen S, Rosenberger C (2008) Renal parenchymal hypoxia, hypoxia adaptation and the pathogenesis of radiocontrast nephropathy. Clin J Am Soc Nephrol 3:288-296

30. Katzberg RW (2005) Contrast medium-induced nephrotoxicity; Which pathway? Radiology 235:752-755

31. Heyman SN, Reichman J, Brezis M (1999) Pathophysioloy of radiocontrast nephropathy. Invest Radiol 34:685-691

32. Persson PB, Hansell P, Liss P (2005) Pathophysiology of contrast medium-induced nephropathy. Kidney International 68:14-22

33. Heyman SN, Rosenberger C, Rosen S (2005) Regional alterations in renal hemodynamcs and oxygenation: a role in contrast mediuminduced nephropathy. Nephrol Dial Transplant 20(Suppl 1):i6-i11

34. Sendeski M, Patzak A, Pallone T, Cao C, Persson AE, Persson PB (2009) Iodixanol, constriction of medullary descending vasa recta, and risk for contrast medium-induced nephropathy. Radiology 251: 697-704

35. Liu ZZ, Viegas VU, Perlewitx A, Lai EY, Persson PB, Patzak A et al (2012) Iodinated contrast media differentially affect afferent and efferent arteriolar tone and reactivity in mice: A possible explanation for reduced glomerular filtration rate. Radiology 265: $762-771$

36. Heyman SN, Rosen S, Khamaisi M, Idee JM, Rosenberger C (2010) Reactive oxygen species and the pathogenesis of radiocontrastinduced nephropathy. Invest Radiol 45:188-195

37. Haller C, Hizoh I (2004) The cytotoxicity of iodinated radiocontrast agents on renal cells in vitro. Invest Radiol 39:149-154

38. ACR manual on contrast media. Version 9 Accessible at: http://www.acr. org/ /media/ACR/Documents/PDF/QualitySafety/Resources/Contrast $\%$ 20Manual/2013_Contrast_Media.pdf Last accessed 24/08/2013

39. Fishbane S (2008) N-Acetylcysteine in the prevention of contrastinduced nephropathy. Clin J Am Soc Nephrol 3:281-287

40. Ellis JH, Cohan RH (2009) Prevention of contrast-induced nephropathy: An overview. Radiol Clin N Am 47:801-811

41. Merten GJ, Burgess PW, Gray LV, Holleman JH, Roush TS, Kowalchuk GJ et al (2004) Prevention of contrast-induced nephropathy with sodium bicarbonate. A randomized controlled trial. JAMA 291: 2328-2334

42. Recio-Mayoral A, Chaparro M, Prado B, Cozar R, Mendez I, Banerjee D et al (2007) The reno-protective effect of hydration with sodium bicarbonate plus $\mathrm{N}$-acetylcysteine in patients undergoing emergency percutaneous coronary intervention: The RENO study. J Am Coll Cardiol 49:1283-1288 
43. Pakfetrat M, Nikoo MH, Malekmakan L, Tabnadeh M, Roozbeh J, Nasab MH et al (2009) A comparison of sodium bicarbonate infusion versus normal saline infusion and its combination with oral acetezolamide for prevention of contrast-induced nephropathy: A randomized, double-blind trial. Int Urol Nephrol 41:629-634

44. Vasheghani-Farahani A, Sadigh G, Kassaian SE, Khatami SM, Fotouhi A, Razavi SA et al (2009) Sodium bicarbonate plus isotonic saline versus saline for prevention of contrast-induced nephropathy in patients undergoing coronary angiography: A randomized controlled trial. Am J Kidney Dis 54:610-618

45. Briguori C, Airdoldi F, D’Andrea D, Bonizzoni E, Morici N, Focaciio A et al (2007) Renal insufficiency following contrast media administration trial (REMEDIAL). A randomized comparison of 3 preventive strategies. Circulation 115:1211-1217

46. Masuda M, Yamada T, Mine T, Morita T, Tamaki S, Tsukamoto Y et al (2007) Comparison of usefulness of sodium bicarbonate versus sodium chloride to prevent contrast-induced nephropathy in patients undergoing an emergent coronary procedure. Am J Cardiol 100:781-786

47. Maioli M, Toso A, Leoncini M, Gallopin M, Tedeschi D, Micheletti $\mathrm{C}$ et al (2008) Sodium bicarbonate versus saline for the prevention of contrast-induced nephropathy in patients with renal dysfunction undergoing coronary angiography or intervention. J Am Coll Cardiol 52:599-604
48. Adolph E, Holdt-Lehmann B, Chatterjee T, Paschka S, Prott A, Schneider $\mathrm{H}$ et al (2008) Renal insufficiency following radiocontrast exposure trial (REINFORCE): A randomized comparison of sodium bicarbonate versus sodium chloride hydration for the prevention of contrast-induced nephropathy. Coron Artery Dis 19:413-419

49. Ozcan EE, Guneri S, Akdeniz B, Akyildiz IZ, Senaslan O, Baris N et al (2007) Sodium bicarbonate, N-acetylcysteine, and saline for prevention of radiocontrast-induced nephropathy. A comparison of 3 regimes for protecting contrast-induced nephropathy in patients undergoing coronary procedures. A single-center prospective controlled trial. Am Heart J 154:539-544

50. Brar SJ, Shen AYJ, Jorgensen MB, Kotlewski A, Aharonian VJ, Desai $\mathrm{N}$ et al (2008) Sodium bicarbonate vs sodium chloride for the prevention of contrast medium-induced nephropathy in patients undergoing coronary angiography. A randomized trial. JAMA 300:1038-1046

51. Kooiman J, Sijpkens YW, Brulez HC, De Vries JPP, Hamming JF, Van der Molen AJ et al (2013) Randomized study of short prehydration with sodium bicarbonate versus standard pre- and posthydration with sodium chloride to prevent contrast induced acute kidney injury: The Salina trial. Accessible at: http://circ.ahajournals. org/cgi/content/meeting_abstract/126/21_MeetingAbstracts/ A 12835 ?sid=0f0efc3a-9dde-4b03-b193-6bf73e392d40 Last accessed 31/05/2013 